\title{
Interstitial lung diseases in the hospitalized patient
}

\author{
Supparerk Disayabutr, Carolyn S. Calfee, Harold R. Collard and Paul J. Wolters ${ }^{*}$
}

\begin{abstract}
Background: Interstitial lung diseases (ILDs) are disorders of the lung parenchyma. The pathogenesis, clinical manifestations, and prognosis of ILDs vary depending on the underlying disease. The onset of most ILDs is insidious, but they may also present subacutely or require hospitalization for management. ILDs that may present subacutely include acute interstitial pneumonia, connective tissue disease-associated ILDs, cryptogenic organizing pneumonia, acute eosinophilic pneumonia, drug-induced ILDs, and acute exacerbation of idiopathic pulmonary fibrosis. Prognosis and response to therapy depend on the type of underlying ILD being managed.

Discussion: This opinion piece discusses approaches to differentiating ILDs in the hospitalized patient, emphasizing the role of bronchoscopy and surgical lung biopsy. We then consider pharmacologic treatments and the use of mechanical ventilation in hospitalized patients with ILD. Finally, lung transplantation and palliative care as treatment modalities are considered.

Summary: The diagnosis of ILD in hospitalized patients requires input from multiple disciplines. The prognosis of ILDs presenting acutely vary depending on the underlying ILD. Patients with advanced ILD or acute exacerbation of idiopathic pulmonary fibrosis have poor outcomes. The mainstay treatment in these patients is supportive care, and mechanical ventilation should only be used in these patients as a bridge to lung transplantation.
\end{abstract}

Keywords: Acute exacerbation of IPF, Pulmonary fibrosis, Interstitial pneumonitis, Interstitial lung disease, Diffuse alveolar damage

\section{Background}

Interstitial lung diseases (ILDs) are diseases that afflict the lung parenchyma. The pathogenesis, clinical manifestations, and prognosis of ILDs depend on the specific underlying disease. Some patients require hospitalization during the course of their illness, and clinicians may face unique challenges while managing the hospitalized patient with ILD. Relevant considerations that are discussed in this manuscript include the ILDs commonly encountered in the hospital, diagnostic approaches, and medical management.

Recently, a multidisciplinary panel of American Thoracic Society/European Respiratory Society (ATS/ERS) members published a revised classification of ILDs based on their clinical, radiologic, and histopathologic findings (Table 1) [1]. The incidence and clinical course of ILDs are variable,

\footnotetext{
* Correspondence: paul.wolters@ucsf.edu

Division of Pulmonary, Critical Care, Allergy and Sleep Medicine, Department of Medicine, University of California, Box 0111, San Francisco, CA 94143-0111, USA
}

depending on the underlying disease. For example, the overall incidence of idiopathic pulmonary fibrosis (IPF) in the United States is estimated to be 6.8 to 16.3 per 100,000 person-years [2], and the incidence increases with advancing age $[2,3]$. Median survival for IPF patients is estimated to be 2 to 5 years from the time of diagnosis $[4,5]$. In contrast, the annual incidence of cryptogenic organizing pneumonia has been estimated to be 2.0 per 100,000 person-years and the median survival 8 years from diagnosis [6].

The clinical presentation of many ILDs is insidious; however, they may also present acutely. In some instances patients need to be hospitalized during the first manifestation of what ultimately proves to be a chronic ILD. Examples of ILDs that usually require hospitalization include acute exacerbations of idiopathic pulmonary fibrosis (AE-IPF), acute interstitial pneumonia (AIP), cryptogenic organizing pneumonia (COP), acute eosinophilic pneumonia (AEP), rapidly progressive or acute exacerbation 
Table 1 Classification of interstitial lung diseases

\begin{tabular}{lll}
\hline Classification & Clinical-radiological-pathological diagnosis & Histopathologic pattern \\
\hline ILDs of known cause & Environmental or drug related & Depends on underlying disease \\
& Connective tissue disease related & Depends on underlying disease \\
Idiopathic interstitial pneumonias (IIPS) & Hypersensitivity pneumonitis & \\
Major IIPs & IPF & \\
$\quad$ Chronic fibrosing IPS & Idiopathic NSIP & UIP \\
Smoking-related IPS & DIP & NSIP \\
Acute/subacute IPS & RB-ILD & DIP \\
COP & Respiratory bronchiolitis \\
Rare IIPs & AIP & Organizing pneumonia \\
Unclassifiable IIPS & Idiopathic LIP & Diffuse alveolar damage \\
Granulomatous lung disorders & Idiopathic PPFE & LIP \\
Other forms of ILD & Sarcoidosis & Elastotic fibrosis of pleura and subpleural parenchyma \\
& LAM & Non-necrotizing granuloma \\
& PLCH & Cysts and proliferation of LAM cells
\end{tabular}

AIP acute interstitial pneumonia, COP cryptogenic organizing pneumonia, DIP desquamative interstitial pneumonia, IP interstitial pneumonia, IPF idiopathic pulmonary fibrosis, LAM lymphagioleiomyomatosis, LIP lymphocytic interstitial pneumonia, NSIP nonspecific interstitial pneumonia, PLCH pulmonary Langerhans cell histiocytosis, PPFE pleuroparenchymalfibroelastosis, RB-ILD respiratory bronchiolitis-associated interstitial lung disease, UIP usual interstitial pneumonia

of connective tissue disease-associated ILDs (CTD-ILD), and drug-induced ILDs.

\section{ILDs commonly requiring hospitalization: clinical presentation and prognosis IPF and acute exacerbations of IPF (AE-IPF)}

Idiopathic pulmonary fibrosis (IPF) is a fibrosing interstitial lung disease associated with aging [7]. Symptomatically, patients report progressive dyspnea and a nonproductive cough. Radiographically, high resolution computed tomography (HRCT) of the chest in a patient with IPF reveals bilateral subpleural reticulation, traction bronchiectasis, a paucity of ground glass opacities, and subpleural honeycombing [8]. The lung pathology of patients with IPF shows temporal heterogeneity of fibrosis that is accentuated subpleurally, with relatively normal lung centrally, microscopic honeycombing, and fibroblast foci. Median survival for IPF is just 3 years; progressive breathlessness and respiratory failure are the most common natural history [5].

Patients may be hospitalized at the time IPF is first recognized, often when the patient has an intercurrent infection, or may suffer an acute exacerbation of their disease (AE-IPF). AE-IPF is the most common cause of acute respiratory deterioration and death in IPF patients $[9,10]$. In some instances AE-IPF may be due to a secondary cause, such as air pollution [11], microaspiration [12], or an intercurrent infection in up to one-third of patients [13].
AE-IPF can occur at any time during the course of disease. Although it may be the first manifestation of IPF $[9,10]$, the frequency of AE-IPF appears to be more common late in the disease course. AE-IPF is characterized by new or worsening of respiratory symptoms, typically in less than 30 days, accompanied by new lung opacities on chest imaging [14]. The characteristic HRCT of the chest shows new ground glass opacities with or without consolidation overlying the typical radiographic changes of IPF [14]. The most common pathological finding is diffuse alveolar damage (DAD) superimposed on the typical pathologic findings of IPF. The outcome of AE-IPF is poor, with a median survival post-AE of approximately 4 months $[10,15]$.

\section{Connective tissue disease-associated ILDs (CTD-ILD)}

Interstitial lung disease has been described in all types of connective tissue disease. Rheumatoid arthritis (RA), polymyositis/dermatomyositis (PM/DM), and systemic sclerosis (SSc) are the most common CTDs that develop an ILD [16]. The majority of patients with CTD-ILD have insidious onset of respiratory symptoms, including shortness of breath, dyspnea on exertion, and cough. Depending on the CTD, nearly all radiographic and histopathologic subtypes of ILD, including usual interstitial pneumonia (UIP), nonspecific interstitial pneumonia (NSIP), DAD, organizing pneumonia (OP), bronchiolitis, cystic lung 
disease, and diffuse alveolar hemorrhage have been reported in patients with CTD. For example, NSIP is the most common radiologic and histopathologic pattern found in patients with SSc or PM/DM [17], a UIP pattern is most common in patients with RA [18], and NSIP with or without areas of OP is most commonly found in antisynthetase syndrome $[19,20]$.

Similar to IPF patients, patients with CTD-ILD may develop subacute respiratory symptoms that occur either as a rapidly progressive CTD-ILD at presentation or an acute exacerbation of preexisting CTD-ILD [21]. The incidence and prevalence of rapidly progressive CTD-ILD varies depending on the underlying CTD, but is most common in PM/DM, especially the amyopathic subtype [22]. RA-ILD is the most common preexisting CTD-ILD that has acute exacerbations. Risk factors for acute exacerbation of CTD-ILD include advanced age, surgical lung biopsy, diagnosis of RA-UIP, and methotrexate treatment $[21,23,24]$. Acute exacerbations of CTD-ILD may occur independent of a flare of extrathoracic manifestations of the CTD and/or while patients are on immunosuppressive treatment. Clinical manifestations mimic conditions that can coexist with underlying CTD including pulmonary infection and treatment-related complications. The radiographic pattern of acute exacerbations of CTD-ILD shows new ground glass opacities superimposed on fibrotic changes that were evident previously. Similarly, lung pathology shows changes of DAD superimposed on a background of lung fibrosis. The outcome of acute exacerbations of CTD-ILD is poor, with hospital mortality rates of $50-100 \%[21,24]$.

\section{Cryptogenic organizing pneumonia (COP)}

Organizing pneumonia may have a known cause or may be cryptogenic (COP) [1]. In both cases, the presentation is usually subacute with symptoms mimicking infection. However, $10-15 \%$ of patients with COP have a rapidly progressive course [25]. Common symptoms are a nonproductive cough, dyspnea on exertion, fever, and malaise. Radiographically, the HRCT shows patchy areas of consolidation in association with airways. Perilobular abnormalities (curved-like bands of parenchymal consolidation with blurred borders along the structures that surround the secondary pulmonary lobule) [26] or reversed halo sign (region of consolidation with central clearing) are highly suggestive of OP [27]. The dominant pathological finding on lung biopsy is intra-alveolar granulation tissue without hyaline membranes [28]. When confronted with a case of organizing pneumonia, it is important to rule out secondary causes (for example, cancer, drugs, CTD, hypersensitivity pneumonitis) before considering the case cryptogenic. The majority of patients with COP have complete clinical and radiological resolution with corticosteroid treatment. Pathological predictors of unfavorable outcome are coexistent lung fibrosis, which suggests the organizing pneumonia is not present in isolation but rather a feature of a more dominant ILD pattern such as NSIP [29].

\section{Acute interstitial pneumonia (AIP)}

AIP is an ILD of unknown cause that presents subacutely and characteristically progresses to severe hypoxemic respiratory failure. Chest radiograph and HRCT findings reveal bilateral airspace opacities in a pattern similar to those seen in patients with acute respiratory distress syndrome (ARDS) [30]. When caring for a patient with suspected AIP, it is critical to first rule out underlying causes of ARDS, which would be treated differently and according to the underlying ARDS risk factor (for example, sepsis, aspiration, pneumonia) [31]. Histopathologically, AIP demonstrates a pattern of DAD that is indistinguishable from acute lung injury of known cause. The prognosis for AIP is poor and worse than that of ARDS, with a reported mortality of greater than $50 \%[32,33]$. The reported progression to fibrosis in a subset of patients may represent acute exacerbations of a previously unrecognized interstitial lung disease rather than progression of AIP to fibrosis [34].

\section{Acute eosinophilic pneumonia (AEP)}

$\mathrm{AEP}$ is an eosinophilic lung disease that can lead to hypoxemic respiratory failure requiring mechanical ventilation. Recent reports suggest that AEP may develop as a hypersensitivity reaction to tobacco smoke or dust exposure [35-37]. Patients present with symptoms of fever, cough, and shortness of breath, and a complete blood count may show peripheral eosinophilia. Radiographically, the HRCT shows bilateral ground glass opacities that are predominantly located in the lung periphery. Cell differential on bronchoalveolar lavage fluid typically contains greater than $30 \%$ eosinophils. Lung histopathology shows marked infiltration of eosinophils in the lung interstitium and alveolar spaces with patchy areas of organizing pneumonia.

\section{Drug-induced interstitial lung disease}

Drug-induced ILD comprises 2-3\% of all ILDs [38]. More than 350 drugs have been reported to cause lung disease $[39,40]$. The diagnosis of drug-induced ILD may be challenging because clinical and radiographic findings are similar to those of many pulmonary diseases. Clues to drug-induced ILD are that the onset of symptoms may correlate to time of first use of the medication (although this relationship is variable and the latency period can be quite long) and a high index of suspicion in all new cases of ILD. Depending on the implicated drug, nearly all radiographic and histopathologic types of lung disease, including NSIP, DAD, OP, eosinophilic pneumonia, 
pulmonary edema, and diffuse alveolar hemorrhage have been reported. NSIP is the most common pathologic pattern of drug-induced ILD.

\section{Comorbidities}

IPF and other fibrotic ILDs may be associated with comorbid illnesses, including pulmonary embolism, pulmonary hypertension, pulmonary infection, pneumothorax, leftsided heart disease, coronary artery disease, lung cancer, emphysema, gastroesophageal reflux disease (GERD), or sleep disorders. Progression of these comorbidities may be the cause of hospitalization and significantly impact patient outcomes $[15,41,42]$. Thus, patients with worsening of respiratory symptoms require evaluation for progressive disease and consideration that these comorbidities may be contributing [43].

\section{Discussion: diagnosis and management of acute manifestations of ILD \\ How are ILDs clinically differentiated in the hospitalized patient?}

Patients with ILD can be hospitalized at the time the ILD is first recognized, or during the progression of an established ILD. When presenting for the first time, clinical, radiographic, and laboratory tests are required to differentiate the cause of the ILD. Historical clues include the patient having symptoms consistent with a connective tissue disease (such as joint pain, swelling, rash, Raynaud's phenomenon, or muscle weakness), use of a medication that causes ILD, or risk factors for organizing pneumonia (medications, cancer, radiation therapy, inhalational injury). Useful laboratory tests include serologies to rule out a connective tissue disease, for example, tests for antinuclear antibody (ANA) and subtypes, rheumatoid factor (RF), cyclic citrullinated peptide (CCP), and synthetase antibodies. These tests should be considered even in patients without systemic symptoms of a CTD, since ILD can be the first manifestation of a CTD.

Chest imaging should be performed in all patients hospitalized with an ILD. Chest radiography is useful as an initial assessment of the amount of lung involvement, but is insensitive to new opacities, especially those overlying preexisting abnormalities. HRCT is more sensitive to detect radiographic abnormalities and does not require iodinated contrast. The pattern and distribution of abnormality on HRCT can aid in refining the differential diagnosis of the ILD and in some cases establish the diagnosis of a specific ILD. In patients without a prior history of ILD, HRCT features that suggest presence of a preexisting ILD are architectural distortion such as traction bronchiectasis or honeycombing. These findings can be used to differentiate AE of a chronic ILD from AIP or ARDS, which typically do not have traction bronchiectasis or honeycombing [44].
The most common cause for hospitalization of patients with previously diagnosed ILD is AE of preexisting ILD [45]. Clinical manifestations include acute progressive dyspnea, cough, with or without fever, and bilateral inspiratory crackles. These exacerbations may be due to progression of the underlying ILD. However, it is important to consider secondary causes such as a superimposed lung infection, left-sided heart failure, diffuse alveolar hemorrhage, or adverse effects of treatment [46]. Pulmonary function tests typically cannot be performed on patients suffering an AE of ILD due to the severity of their illness. If performed, they typically demonstrate progressive reduction of forced vital capacity (FVC) and diffusing capacity for carbon monoxide (DLCO).

\section{What is the role of bronchoscopy?}

Bronchoscopy with bronchoalveolar lavage (BAL) or transbronchial biopsy may be useful in cases where clinical history and chest imaging cannot establish a diagnosis. Prior to bronchoscopy, the risk of BAL should be carefully considered, because BAL can lead to worsening of hypoxemia, especially in spontaneously breathing patients. BAL can be used in patients with acute ILD or AE-IPF to confirm lung infection by bacterial culture and PCR for viruses. However, a negative BAL analysis does not definitively exclude infection. Its sensitivity is no better than $70 \%$ for many infections. BAL analysis can be particularly useful in immunosuppressed patients with CTD-ILD, because infections such as Pneumocystis jirovecii in patients with CTD-ILD (especially dermatomyositis patients who are at particularly high risk for Pneumocystis jirovecii infection) may have a similar radiographic appearance to an acute exacerbation of CTD-ILD.

BAL cell count and differential may be useful in the diagnostic workup of the hospitalized patient with ILD. It is particularly helpful in establishing the diagnosis of AEP, where eosinophil counts greater than $30 \%$ in BAL fluid are consistent with the diagnosis of AEP [36]. BAL cell count and differential are less helpful in patients with AIP or AE-IPF. The BAL cell count and differential for these diseases are typically characterized by an elevated percentage of neutrophils, and slight lymphocytosis. These cellular differentials are similar to those found in patients with bacterial or viral infections, restricting use of the cell differential in differentiating AE-ILD from an infection in an ILD patient.

Transbronchial biopsy is of limited utility in the management of the hospitalized ILD patient due to the small size of the tissue sample obtained, unless organizing pneumonia is suspected. In these patients, transbronchial biopsy yields the pathologic pattern of organizing pneumonia in up to $64 \%$ of patients [47]. 


\section{What is the role of surgical lung biopsy?}

If medically necessary, surgical lung biopsy (SLB) can be used to differentiate interstitial lung disease of unknown cause, even in mechanically ventilated patients [48], and may lead to a change in treatment in hospitalized patients undergoing the procedure $[48,49]$. Lung biopsy may be especially useful in hospitalized patients presenting with ILD for the first time when clinical history, laboratory tests, and chest imaging do not establish the diagnosis. Lung biopsy may also be useful in patients with a clinical presentation consistent with AIP or idiopathic ARDS, though a careful evaluation of the risks and benefits of empiric therapy versus biopsy must be undertaken first [50]. In cases of acute worsening of a previously recognized ILD, histopathology typically shows a DAD pattern overlying a pattern of fibrotic lung disease. Because the histopathological pattern of AEs is reliably consistent with abnormalities on HRCT and because 30-day mortality of $\mathrm{AE}$ patients is high, a surgical biopsy in patients with an $\mathrm{AE}$ of previously recognized ILD is rarely performed [45].

\section{What pharmacologic treatments should be administered?}

There are no well-designed, randomized, double blind placebo controlled trials to guide the pharmacologic therapy of the hospitalized ILD patient. Due to the challenge in differentiating lung infection from an acute presentation of ILD or acute exacerbation of preexisting ILD, treatment with broad-spectrum antibiotics should be considered in all patients. Nevertheless, clinical experience suggests that patients with specific ILDs improve with corticosteroid treatment. ILDs that appear to be steroid responsive are COP, AEP, some cases of CTD-ILD (importantly, high doses of corticosteroids are not recommended in SSc-ILD), and drug-induced ILDs. Response rates correspond to the underlying pathology, with eosinophilic pneumonia and OP being the most steroid responsive. The majority of patients with COP respond to corticosteroid treatment and have resolution of symptoms and radiographic abnormalities within weeks to months of initiating therapy $[1,51]$. A typical initial dose of corticosteroid is $1 \mathrm{mg} / \mathrm{kg} /$ day of prednisone, which is then tapered to $20 \mathrm{mg} /$ day after several weeks. Relapses may occur when treatment is stopped or rapidly tapered [51]. One year of treatment is often recommended [28, 51]. Corticosteroids are also useful in the management of AEP. Patients with AEP can have dramatic clinical improvement within 24-48 h after initiating corticosteroid treatment $[36,52]$.

Whether corticosteroids or immunosuppressants benefit patients with AE-IPF or AE of ILD other than IPF is uncertain. Corticosteroids may be beneficial when chest imaging suggests organizing pneumonia is present. Because of reports that azathioprine is associated with worse outcomes in patients with IPF or other forms of DAD, the use of cytotoxic medications should not be used for management of these patients [53]. In contrast to AE-IPF, there is a biologic rationale for treating AE of CTD-ILD patients with immunosuppressants. The driving force behind these diseases is believed to be hyperactivity of the immune system. Therefore, immunosuppressants such as mycophenolate mofetil, cyclophosphamide, or azathioprine may be useful in these patients.

\section{What is the role of noninvasive ventilation and mechanical ventilation?}

Patients hospitalized with an interstitial lung disease may have gas exchange abnormalities that require advanced ventilator support. The therapeutic options are high flow nasal cannula oxygen, noninvasive ventilation, or mechanical ventilation. There are a few small retrospective studies evaluating the role of noninvasive mechanical ventilation (NIV) in ILD patients presenting with acute respiratory failure. These studies report that use of NIV prevented endotracheal intubation in the minority of patients [54-57]. Of survivors in the NIV group, the majority died within 90 days following hospital discharge [56]. Furthermore, the majority of IPF patients failing NIV that subsequently were managed with mechanical ventilation died in the ICU $[56,57]$. From these studies, it appears that the outcome of ILD patients requiring NIV is poor, though data from randomized controlled trials is lacking. However, NIV may provide benefit in a small subset of patients by preventing the need for mechanical ventilation.

If a patient is mechanically ventilated, the ventilator strategies applied often are similar to those used to manage patients with ARDS, because the pathological abnormalities of the lungs and alterations in lung mechanics are similar in these conditions [58]. Mechanical ventilation has been shown to improve oxygenation in $25 \%$ of patients but did not influence levels of $\mathrm{PaCO}_{2}$ [59]. Unlike ARDS patients, patients with chronic ILD may have little or no recruitable lung and are prone to barotrauma due to overdistension of alveoli [58]. A case series of 94 patients with ILD and acute respiratory failure reported that low tidal volume was not associated with improvement of outcome and use of high levels of positive end-expiratory pressure (PEEP) was independently associated with lower shortterm and long-term survival [60]. When patients with advanced lung fibrosis are managed with mechanical ventilation, the majority die in the intensive care unit without being liberated from the ventilator $[54,59]$. Overall, these studies suggest that mechanical ventilation does not improve outcome in patients with AE-IPF or advanced lung fibrosis. The goals of mechanical ventilation should be carefully considered prior to offering it to patients with advanced ILD or an AE-IPF, as the prognosis is poor once mechanical ventilation is required to manage their illness. 


\section{What is the role of lung transplantation?}

Pharmacological treatment and supportive measures may be ineffective for treating the hospitalized patient with ILD. This is especially true for patients with an acute worsening of IPF or those with advanced lung fibrosis. In these circumstances, lung transplantation may be the only remaining treatment option to consider in managing their disease. IPF is the second most common indication for lung transplantation [61]. Transplantation should be considered early in the hospitalization for patients with AE-IPF in order to arrange transfer to a transplant center for further evaluation and management. Contraindications to transplantation at many centers include age greater than 70 , elevated BMI ( $>30$ at most centers), active cancer, lack of dependable social support, recent substance abuse, or multiple medical comorbidities (Table 2) [62]. Mechanical ventilation or extracorporeal membrane oxygenation (ECMO) may be used as a bridging therapy to lung transplantation in select patients with ILD and severe gas exchange abnormalities [63]. When required prior to transplantation, mechanical ventilation has been associated with greater mortality in the first 6 months after transplant but does not appear to impact long-term survival [64].

\section{When should palliative care be emphasized as the main treatment goal?}

Because a significant percentage of patients hospitalized with advanced lung fibrosis or an AE of ILD succumb to

Table 2 Contraindications for lung transplantation

\begin{tabular}{|c|c|}
\hline \multirow[t]{7}{*}{ Absolute contraindications } & $\begin{array}{l}\text { - Active malignancy in the last } 2 \text { years } \\
\text { except for cutaneous squamous and } \\
\text { basal cell tumors }\end{array}$ \\
\hline & $\begin{array}{l}\text { - Untreatable dysfunction of another } \\
\text { major organ }\end{array}$ \\
\hline & - Incurable extrapulmonary infection \\
\hline & - Significant chest wall or spine deformity \\
\hline & $\begin{array}{l}\text { - Inability to follow through with medical } \\
\text { therapy }\end{array}$ \\
\hline & - Lack of dependable social support \\
\hline & $\begin{array}{l}\text { - Substance addiction within the last } \\
6 \text { months }\end{array}$ \\
\hline \multirow[t]{6}{*}{ Relative contraindications } & $\begin{array}{l}\text { - Age older than } 70 \text { years (65 in some } \\
\text { centers) }\end{array}$ \\
\hline & - Critical or unstable clinical condition \\
\hline & $\begin{array}{l}\text { - Severely limited functional status with } \\
\text { poor rehabilitation potential }\end{array}$ \\
\hline & $\begin{array}{l}\text { - Colonization with highly resistant or } \\
\text { virulent bacteria, fungi }\end{array}$ \\
\hline & $\begin{array}{l}\text { - Severe obesity (a body mass index } \\
>30 \mathrm{~kg} / \mathrm{m}^{2} \text { ) }\end{array}$ \\
\hline & - Severe or symptomatic osteoporosis \\
\hline
\end{tabular}

their disease, the prognosis, probable outcome on mechanical ventilation, and role of palliative care should be considered once the diagnosis is established in these patients. When patients are hospitalized with acute respiratory failure, the role of life support and the risks of mechanical ventilation should be discussed and, when appropriate, palliative care interventions pursued as the main goals of therapy.

\section{Summary}

Diagnosis of acute exacerbation of chronic ILD or acute ILD should be considered if indicated by clinical or radiological or histopathologic findings and other mimic conditions are already excluded. The mainstay treatment of these conditions is supportive care. Corticosteroids or immunosuppressants are indicated in some acute ILDs, including COP and AEP. Mechanical ventilation should only be offered in select cases, most notably patients with reversible processes or those considered candidates for urgent lung transplantation.

\section{Abbreviations}

AIP: acute interstitial pneumonia; BAL: bronchoalveolar lavage; COP: cryptogenic organizing pneumonia; CTD-ILD: connective tissue disease-associated interstitial lung disease; DAD: diffuse alveolar damage; DLCO: diffusing capacity for carbon monoxide; DM: dermatomyositis; FVC: forced vital capacity; GERD: gastroesophageal reflux disease; HRCT: high resolution computed tomography; IIP: idiopathic interstitial pneumonia; ILD: interstitial lung disease; IPF: idiopathic pulmonary fibrosis; NIV: noninvasive mechanical ventilation; NSIP: nonspecific interstitial pneumonia; PM: polymyositis; RA: rheumatoid arthritis; SLB: surgical lung biopsy; SSc: systemic sclerosis; UIP: usual interstitial pneumonia.

\section{Competing interests}

The authors declare that they have no competing interests.

\section{Authors' contributions}

SD, CSC, HRC, and PJW conceived of the manuscript. SD reviewed the literature and drafted the original and final versions of the manuscript. SD, CSC, HRC, and PJW critically revised drafts of the manuscript and approved the final version.

\section{Acknowledgements}

This work was funded by the Nina Ireland Program for Lung Health.

Received: 22 May 2015 Accepted: 11 September 2015

Published online: 25 September 2015

\section{References}

1. Travis WD, Costabel U, Hansell DM, King Jr TE, Lynch DA, Nicholson AG, et al. An official American Thoracic Society/European Respiratory Society statement: Update of the international multidisciplinary classification of the idiopathic interstitial pneumonias. Am J Respir Crit Care Med. 2013;188:733-48.

2. Raghu G, Weycker D, Edelsberg J, Bradford WZ, Oster G. Incidence and prevalence of idiopathic pulmonary fibrosis. Am J Respir Crit Care Med. 2006;174:810-6.

3. Raghu G, Chen SY, Yeh WS, Maroni B, Li Q, Lee YC, et al. Idiopathic pulmonary fibrosis in US Medicare beneficiaries aged 65 years and older: incidence, prevalence, and survival, 2001-11. Lancet Respir Med. 2014.

4. Bjoraker JA, Ryu JH, Edwin MK, Myers JL, Tazelaar HD, Schroeder DR, et al. Prognostic significance of histopathologic subsets in idiopathic pulmonary fibrosis. Am J Respir Crit Care Med. 1998;157:199-203.

5. Ley B, Collard HR, King Jr TE. Clinical course and prediction of survival in idiopathic pulmonary fibrosis. Am J Respir Crit Care Med. 2011;183:431-40. 
6. Gudmundsson G, Sveinsson O, Isaksson HJ, Jonsson S, Frodadottir H, Aspelund T. Epidemiology of organising pneumonia in Iceland. Thorax. 2006;61:805-8

7. Wolters PJ, Collard HR, Jones KD. Pathogenesis of idiopathic pulmonary fibrosis. Annu Rev Pathol. 2014;9:157-79.

8. Raghu G, Collard HR, Egan JJ, Martinez FJ, Behr J, Brown KK, et al. An official ATS/ERS/JRS/ALAT statement: idiopathic pulmonary fibrosis: evidence-based guidelines for diagnosis and management. Am J Respir Crit Care Med. 2011;183:788-824.

9. Kim DS, Park JH, Park BK, Lee JS, Nicholson AG, Colby T. Acute exacerbation of idiopathic pulmonary fibrosis: frequency and clinical features. Eur Respir J. 2006;27:143-50

10. Song JW, Hong SB, Lim CM, Koh Y, Kim DS. Acute exacerbation of idiopathic pulmonary fibrosis: incidence, risk factors and outcome. Eur Respir J. 2011;37:356-63.

11. Johannson KA, Vittinghoff E, Lee K, Balmes JR, Ji W, Kaplan GG, et al. Acute exacerbation of idiopathic pulmonary fibrosis associated with air pollution exposure. Eur Respir J. 2014;43:1124-31.

12. Lee JS, Song JW, Wolters PJ, Elicker BM, King Jr TE, Kim DS, et al. Bronchoalveolar lavage pepsin in acute exacerbation of idiopathic pulmonary fibrosis. Eur Respir J. 2012;39:352-8.

13. Huie TJ, Olson AL, Cosgrove GP, Janssen WJ, Lara AR, Lynch DA, et al. A detailed evaluation of acute respiratory decline in patients with fibrotic lung disease: aetiology and outcomes. Respirology. 2010;15:909-17.

14. Akira M, Kozuka T, Yamamoto S, Sakatani M. Computed tomography findings in acute exacerbation of idiopathic pulmonary fibrosis. Am J Respir Crit Care Med. 2008;178:372-8

15. Collard HR, Yow E, Richeldi L, Anstrom KJ, Glazer C, IPFnet investigators. Suspected acute exacerbation of idiopathic pulmonary fibrosis as an outcome measure in clinical trials. Respir Res. 2013;14:73-9921-14-73.

16. Vij R, Strek ME. Diagnosis and treatment of connective tissue diseaseassociated interstitial lung disease. Chest. 2013;143:814-24.

17. King Jr TE. Clinical advances in the diagnosis and therapy of the interstitial lung diseases. Am J Respir Crit Care Med. 2005;172:268-79.

18. Assayag D, Elicker BM, Urbania TH, Colby TV, Kang BH, Ryu JH, et al. Rheumatoid arthritis-associated interstitial lung disease: radiologic identification of usual interstitial pneumonia pattern. Radiology. 2014;270:583-8.

19. Arakawa H, Yamada H, Kurihara Y, Nakajima Y, Takeda A, Fukushima $Y$, et al. Nonspecific interstitial pneumonia associated with polymyositis and dermatomyositis: serial high-resolution CT findings and functional correlation. Chest. 2003;123:1096-103.

20. Debray MP, Borie R, Revel MP, Naccache JM, Khalil A, Toper C, et al. Interstitial lung disease in anti-synthetase syndrome: initial and follow-up $C T$ findings. Eur J Radiol. 2015;84:516-23.

21. Park IN, Kim DS, Shim TS, Lim CM, Lee SD, Koh Y, et al. Acute exacerbation of interstitial pneumonia other than idiopathic pulmonary fibrosis. Chest. 2007;132:214-20

22. Sato S, Kuwana M. Clinically amyopathic dermatomyositis. Curr Opin Rheumatol. 2010;22:639-43.

23. Hozumi H, Nakamura Y, Johkoh T, Sumikawa H, Colby TV, Kono M, et al. Acute exacerbation in rheumatoid arthritis-associated interstitial lung disease: a retrospective case control study. BMJ Open. 2013;3, e003132. -2013-003132.

24. Suda T, Kaida Y, Nakamura Y, Enomoto N, Fujisawa T, Imokawa S, et al. Acute exacerbation of interstitial pneumonia associated with collagen vascular diseases. Respir Med. 2009:103:846-53.

25. Cohen AJ, King Jr TE, Downey GP. Rapidly progressive bronchiolitis obliterans with organizing pneumonia. Am J Respir Crit Care Med. 1994;149:1670-5.

26. Ujita M, Renzoni EA, Veeraraghavan S, Wells AU, Hansell DM. Organizing pneumonia: perilobular pattern at thin-section CT. Radiology. 2004;232:757-61.

27. Kim SJ, Lee KS, Ryu YH, Yoon YC, Choe KO, Kim TS, et al. Reversed halo sign on high-resolution CT of cryptogenic organizing pneumonia: diagnostic implications. AJR Am J Roentgenol. 2003;180:1251-4.

28. Cordier JF. Cryptogenic organising pneumonia. Eur Respir J. 2006;28:422-46.

29. Yousem SA, Lohr RH, Colby TV. Idiopathic bronchiolitis obliterans organizing pneumonia/cryptogenic organizing pneumonia with unfavorable outcome: pathologic predictors. Mod Pathol. 1997;10:864-71.

30. Johkoh T, Muller NL, Taniguchi H, Kondoh Y, Akira M, Ichikado K, et al. Acute interstitial pneumonia: thin-section CT findings in 36 patients. Radiology. 1999;211:859-63.

31. Janz DR, Ware LB. Approach to the patient with the acute respiratory distress syndrome. Clin Chest Med. 2014;35:685-96.
32. Bouros D, Nicholson AC, Polychronopoulos V, du Bois RM. Acute interstitial pneumonia. Eur Respir J. 2000;15:412-8.

33. Vourlekis JS, Brown KK, Cool CD, Young DA, Cherniack RM, King TE, et al. Acute interstitial pneumonitis. Case series and review of the literature. Medicine (Baltimore). 2000;79:369-78.

34. Araya J, Kawabata Y, P J, Uchiyama T, Ogata H, Sugita Y. Clinically occult subpleural fibrosis and acute interstitial pneumonia a precursor to idiopathic pulmonary fibrosis? Respirology. 2008;13:408-12.

35. Badesch DB, King Jr TE, Schwarz MI. Acute eosinophilic pneumonia: a hypersensitivity phenomenon? Am Rev Respir Dis. 1989;139:249-52.

36. Philit F, Etienne-Mastroianni B, Parrot A, Guerin C, Robert D, Cordier JF. Idiopathic acute eosinophilic pneumonia: a study of 22 patients. Am J Respir Crit Care Med. 2002;166:1235-9.

37. Shorr AF, Scoville SL, Cersovsky SB, Shanks GD, Ockenhouse CF, Smoak BL, et al. Acute eosinophilic pneumonia among US Military personnel deployed in or near Iraq. JAMA. 2004;292:2997-3005.

38. Thomeer MJ, Costabe U, Rizzato G, Poletti V, Demedts M. Comparison of registries of interstitial lung diseases in three European countries. Eur Respir J Suppl. 2001;32:114s-118s.

39. The Drug-Induced Respiratory Disease Website [http://pneumotox.com] Accessed 23 September 2015.

40. Camus P, Rosenow EC,3rd. latrogenic lung disease. Clin Chest Med. 2004;25:XIII-XIX

41. Daniels CE, Yi ES, Ryu JH. Autopsy findings in 42 consecutive patients with idiopathic pulmonary fibrosis. Eur Respir J. 2008:32:170-4.

42. Panos RJ, Mortenson RL, Niccoli SA, King Jr TE. Clinical deterioration in patients with idiopathic pulmonary fibrosis: causes and assessment. Am J Med. 1990;88:396-404.

43. King C, Nathan SD. Identification and treatment of comorbidities in idiopathic pulmonary fibrosis and other fibrotic lung diseases. Curr Opin Pulm Med. 2013;19:466-73.

44. Fujimoto $K$, Taniguchi H, Johkoh T, Kondoh Y, Ichikado K, Sumikawa H, et al. Acute exacerbation of idiopathic pulmonary fibrosis: high-resolution $C T$ scores predict mortality. Eur Radiol. 2012;22:83-92.

45. Collard HR, Moore BB, Flaherty KR, Brown KK, Kaner RJ, King Jr TE, et al. Acute exacerbations of idiopathic pulmonary fibrosis. Am J Respir Crit Care Med. 2007;176:636-43.

46. Johannson K, Collard HR. Acute exacerbation of idiopathic pulmonary fibrosis: a proposal. Curr Respir Care Rep. 2013;2:10.1007/s13665-013-0065-X

47. Poletti V, Cazzato S, Minicuci N, Zompatori M, Burzi M, Schiattone ML. The diagnostic value of bronchoalveolar lavage and transbronchial lung biopsy in cryptogenic organizing pneumonia. Eur Respir J. 1996;9:2513-6.

48. Lim SY, Suh GY, Choi JC, Koh WJ, Lim SY, Han J, et al. Usefulness of open lung biopsy in mechanically ventilated patients with undiagnosed diffuse pulmonary infiltrates: influence of comorbidities and organ dysfunction. Crit Care. 2007;11:R93.

49. Tiitto L, Heiskanen U, Bloigu R, Paakko P, Kinnula V, Kaarteenaho-Wiik R. Thoracoscopic lung biopsy is a safe procedure in diagnosing usual interstitial pneumonia. Chest. 2005;128:2375-80.

50. Palakshappa JA, Meyer NJ. Which patients with ARDS benefit from lung biopsy? Chest. 2015. doi: 10.1378/chest.15-0076.

51. Lazor R, Vandevenne A, Pelletier A, Leclerc P, Court-Fortune I, Cordier JF. Cryptogenic organizing pneumonia. Characteristics of relapses in a series of 48 patients. The Groupe d'Etudes et de Recherche sur les Maladles "Orphelines" Pulmonaires (GERM"O"P). Am J Respir Crit Care Med. 2000;162:571-7.

52. Pope-Harman AL, Davis WB, Allen ED, Christoforidis AJ, Allen JN. Acute eosinophilic pneumonia. A summary of 15 cases and review of the literature. Medicine (Baltimore). 1996;75:334-42.

53. Idiopathic Pulmonary Fibrosis Clinical Research Network, Raghu G, Anstrom KJ, King Jr TE, Lasky JA, Martinez FJ. Prednisone, azathioprine, and N-acetylcysteine for pulmonary fibrosis. N Engl J Med. 2012;366:1968-77.

54. Blivet S, Philit F, Sab JM, Langevin B, Paret M, Guerin C, et al. Outcome of patients with idiopathic pulmonary fibrosis admitted to the ICU for respiratory failure. Chest. 2001;120:209-12.

55. Saydain G, Islam A, Afessa B, Ryu JH, Scott JP, Peters SG. Outcome of patients with idiopathic pulmonary fibrosis admitted to the intensive care unit. Am J Respir Crit Care Med. 2002;166:839-42.

56. Vianello A, Arcaro G, Battistella L, Pipitone E, Vio S, Concas A, et al. Noninvasive ventilation in the event of acute respiratory failure in patients with idiopathic pulmonary fibrosis. J Crit Care. 2014;29:562-7. 
57. Yokoyama T, Kondoh Y, Taniguchi H, Kataoka K, Kato K, Nishiyama O, et al. Noninvasive ventilation in acute exacerbation of idiopathic pulmonary fibrosis. Intern Med. 2010;49:1509-14.

58. Nava S, Rubini F. Lung and chest wall mechanics in ventilated patients with end stage idiopathic pulmonary fibrosis. Thorax. 1999;54:390-5.

59. Mollica C, Paone G, Conti V, Ceccarelli D, Schmid G, Mattia P, et al. Mechanical ventilation in patients with end-stage idiopathic pulmonary fibrosis. Respiration. 2010;79:209-15.

60. Fernandez-Perez ER, Yilmaz M, Jenad H, Daniels CE, Ryu JH, Hubmayr RD, et al. Ventilator settings and outcome of respiratory failure in chronic interstitial lung disease. Chest. 2008;133:1113-9.

61. Orens JB, Estenne M, Arcasoy S, Conte JV, Corris P, Egan JJ, et al. International guidelines for the selection of lung transplant candidates: 2006 update-a consensus report from the Pulmonary Scientific Council of the International Society for Heart and Lung Transplantation. J Heart Lung Transplant. 2006;25:745-55.

62. Whitson BA, Hayes Jr D. Indications and outcomes in adult lung transplantation. J Thorac Dis. 2014;6:1018-23.

63. Hoopes CW, Kukreja J, Golden J, Davenport DL, Diaz-Guzman E, Zwischenberger JB. Extracorporeal membrane oxygenation as a bridge to pulmonary transplantation. J Thorac Cardiovasc Surg. 2013;145:862-7. discussion 867-8,

64. Singer JP, Blanc PD, Hoopes C, Golden JA, Koff JL, Leard LE, et al. The impact of pretransplant mechanical ventilation on short- and long-term survival after lung transplantation. Am J Transplant. 2011;11:2197-204.

\section{Submit your next manuscript to BioMed Central and take full advantage of:}

- Convenient online submission

- Thorough peer review

- No space constraints or color figure charges

- Immediate publication on acceptance

- Inclusion in PubMed, CAS, Scopus and Google Scholar

- Research which is freely available for redistribution 